\title{
ВЛИЯНИЕ ЭЛЕКТРОННЫХ СИГАРЕТ И СИСТЕМ НАГРЕВАНИЯ ТАБАКА НА ОРГАНЫ И ТКАНИ ПОЛОСТИ РТА
}

\section{EFFECTS OF ELECTRONIC CIGARETTES AND TOBACCO HEATING SYSTEM \\ TO THE ORGANS AND TISSUES OF THE ORAL CAVITY}

A. Kishkan

Summary. The increase in the use of electronic cigarettes (e-cigarettes) among young people and the lack of knowledge about the health effects of smoking in the short and long term are worrying. Although the oral cavity is the first to directly interact with e-cigarette aerosol, research on potential oral lesions is still limited and there is some debate about safety. In this study, we summarized the effects of e-cigarettes on oral health.

Keywords: electronic cigarettes, vaping, tobacco heating systems, impact, oral diseases.

\author{
Кишкань Алексей Алексеевич \\ Аспирант, Первый Московский государственный \\ медицинский университет имени И. М. Сеченова \\ kishkan92@bk.ru
}

Аннотация. Вызывает беспокойство рост использования электронных сигарет (е-сигареты) среди молодежи и отсутствие знаний о влиянии курения на здоровье в краткосрочной и долгосрочной перспективе. Хотя полость рта является первой, которая напрямую взаимодействует с аэрозолем для электронных сигарет, исследования потенциальных поражений полости рта все еще ограничены, и есть некоторые споры о безопасности. В ходе проведенного исследования мы обобщили влияние электронных сигарет на здоровье полости рта.

Ключевые слова: электронные сигареты, вейпинг, системы нагревания табака, влияние, заболевания полости рта.

тель. Процесс нанесения на устройство и производство аэрозоля очень напоминают курение сигарет, что делает электронные сигареты особенно привлекательной альтернативой для курильщиков [3].

Электронные сигареты не сжигают табак. Вместо этого у них есть картриджи, заполненные жидкостью, которая может содержать ароматизаторы, никотин, тетрагидроканнабинол (THC) или каннабиноидные (CBD) масла и другие химические вещества. Электронная сигарета нагревает жидкие химические вещества до пара или пара, который вдыхает человек, поэтому их использование часто называется «вейпингом» [4].

Хотя типы и концентрации токсинов зависят от марки и устройства, все электронные сигареты содержат вредные вещества. Они стали доступны в Соединенных Штатах только с 2006 года. В результате исследований, посвященных их долгосрочным рискам для здоровья, мало. Из-за рисков Управление по санитарному надзору за качеством пищевых продуктов и медикаментов США (FDA) предприняло первые шаги по регулированию этих продуктов в 2016 году, хотя все еще существует ограниченное регулирование содержимого электронных жидкостей и устройств [5].

По состоянию на сентябрь 2019 года в Соединенных Штатах зарегистрировано более 800 случаев тяжелого заболевания легких, в том числе 12 смертельных слу- 
чаев. Все пострадавшие пациенты сообщили о предыдущем использовании устройств для вейпинга, но нет подтвержденной связи с конкретным устройством для вейпинга или электронной жидкостью. Отчеты Центров по контролю за заболеваниями США (CDC) на данный момент показывают, что большинство пациентов с этим заболеванием легких сообщали об использовании продуктов, содержащих ТГК, но многие также сообщили об использовании никотина. Некоторые пациенты сообщили, что они просто курили никотинсодержащие электронные сигареты [6].

В девяти исследованиях оценивали физиологические эффекты использования электронных сигарет. Электронные сигареты часто продаются как «безопасные» продукты. Однако, хотя вдыхаемые соединения, связанные с электронными сигаретами, могут быть меньше и менее токсичны, чем соединения из традиционных сигарет, данные, позволяющие установить, является ли использование электронных сигарет в целом менее вредным для отдельного пользователя, чем традиционные сигареты, неубедительны [7].

Потенциальному влиянию электронных сигарет на здоровье полости рта уделялось очень мало внимания, что удивительно, учитывая тесную связь табачного дыма с несколькими патогенными процессами в полости рта, а также тот факт, что аэрозоли электронных сигарет сначала контактируют с тканями полости рта, когда они самые горячие и концентрированные.

В 2014 году был проведен систематический обзор литературы, чтобы установить, существуют ли какие-либо доказательства воздействия на здоровье полости рта от использования электронных сигарет. В результате было выявлено несколько соответствующих исследований. Было проведено несколько анкет / опросов пользователей, в которых неоднократно указывались «сухость и раздражение во рту и горле» как один из наиболее распространенных побочных эффектов использования электронных сигарет. Исследование фибробластов периодонтальной связки in vitro продемонстрировало снижение пролиферации фибробластов с добавками ментола. В настоящее время во Франции проводится пятилетнее многоцентровое проспективное обсервационное когортное исследование, и одним из критериев его оценки является госпитализация по поводу рака полости рта. Было направлено пилотное исследование по изучению перфузии слизистой оболочки полости рта во внутриротовых свободных лоскутах в публикацию, но результаты в настоящее время не опубликованы [8].

У людей, регулярно использующих электронные сигареты, нет заметно отличающихся друг от друга бактериальных сообществ полости рта или кишечника по сравне- нию с контрольной группой некурящих. В исследовании Stewart C.J. и соавт. обнаружили, что курение табака было связано со значительными различиями в бактериальных профилях в образцах кала, щек и слюны. По сравнению с контрольной группой, воздействие ЭК не имело никакого значения для микробных сообществ полости рта или кишечника. Различия в кишечных сообществах курильщиков табака были связаны с более высокой относительной численностью Prevotella и более низкой относительной численностью Bacteroides. Другие конечные точки, помимо микробиоты, будут важны при определении воздействия ЭК на здоровье и болезни человека. В то время как использование ЭК продолжает расти, авторы подчеркивают необходимость более глубокого понимания прямого краткосрочного и долгосрочного воздействия пара на состав и функции микробиома [9].

Электронные сигареты могут способствовать развитию заболеваний пародонта: в клиническом исследовании 46 с участием 3 групп (33 курильщика сигарет, 31 пользователь электронных сигарет и 30 никогда не куривших) индекс налета во рту и глубина зондирования $>4$ мм были значительно выше среди горючих сигарет. курильщики, за которыми следуют пользователи электронных сигарет, по сравнению с некурящими. О боли в деснах также чаще сообщали курильщики горючих сигарет, чем пользователи электронных сигарет. Однако, хотя воспаление пародонта и субъективно воспринимаемые оральные симптомы были выше при использовании CCS, электронные сигареты также способствовали неблагоприятному здоровью пародонта у их пользователей [10].

Эти клинические исследования предполагают тесное взаимодействие между электронной сигаретой и пародонтом, что может привести к ухудшению здоровья полости рта. Необходимы дальнейшие исследования, чтобы подтвердить эти наблюдения и определить основные причины этих нежелательных эффектов электронных сигарет, а также механизмы, участвующие в повреждении пародонта. Будущие исследования должны дать ответ на вопрос: в какой степени взаимодействие между электронной сигаретой и оральным пародонтом связано с заболеваниями пародонта [11].

Электронные сигареты могут способствовать кариесу зубов: PG и VG придают жидкостям для электронных сигарет высокую вязкость. В результате аэрозоли от этих жидкостей могут прилипать к незащищенным поверхностям, таким как мягкие и твердые ткани в полости рта, а также к зубным имплантатам. Это взаимодействие может, в свою очередь, способствовать адгезии бактерий, приводящей к инфекциям полости рта, таким как кариес. Кроме того, кариесу зубов может способствовать добавление ароматизаторов с добавлением сахаров. Сахароза, сукралоза и сахарный спирт являются известными 
добавками к жидкостям для электронных сигарет, которые усиливают вкус и аромат [12].

Недавнее исследование показало, что аэрозоли от электронных сигарет увеличивают адгезию Streptococcus mutans к эмали и способствуют образованию биопленки. Действительно, эмаль, подвергнутая воздействию ароматизированных аэрозолей электронных сигарет, показала меньшую твердость по сравнению с эмалью, подвергнутой контролю без ароматизаторов. Эта инициируемая бактериями деминерализация эмали была связана с высоким содержанием сложных эфиров (этилбутират, гексилацетат и триацетин), обнаруженных в жидкостях для электронных сигарет. Поскольку коммерческие жидкости для электронных сигарет содержат несколько добавок на разных уровнях, включая сахарозу, заменители сахара и кислоты, взаимодействие с зубами может варьироваться от жидкости к жидкости.

Необходимы дополнительные исследования для информирования пользователей и стоматологов о профилактике кариеса, вызванного электронными сигаретами. В самом деле, конкретный исследовательский вопрос будет заключаться в следующем: насколько аэрозоли от электронных сигарет увеличивают заболеваемость кариесом зубов среди пользователей [13].

Электронные сигареты могут оказывать неблагоприятное воздействие на зубы и ткани, поддерживающие зубы. При использовании электронных сигарет аэрозоль вступает в прямой контакт с зубами и может отрицательно повлиять на структуру зубов. Cho48 изучил связь между употреблением электронных сигарет и некоторыми оральными симптомами среди подростков и выявил значительно повышенный риск повреждения зубов при курении. Действительно, 11,4\% тех, кто употреблял электронные сигареты, самостоятельно сообщили о треснувшем или сломанном зубе за последние 12 месяцев, 18,5\% сообщили о боли в деснах и / или кровотечении и $11,0 \%$ сообщили о боли в языке с болями внутри щеки и без них [14].

Эти наблюдения подтверждаются исследованием in vitro, проведенным с образцами бычьей эмали, подвергнутыми воздействию аэрозолей от электронных сигарет, с использованием различных жидких ароматизаторов (нейтральный, ментол и табак) и содержания никотина (0, 12 и 18 мг). Исследование показало, что аэрозоли с различным содержанием никотина и ароматизаторами меняют цвет эмали и снижают яркость; ароматизированные жидкости вызывали большее изменение цвета. Эти данные свидетельствуют о том, что электронные сигареты негативно влияют на структуру и эстетику зубов.

Влияние электронных сигарет на сухость во рту и другие формы раздражения: в исследовании, осно- ванном на сообщениях пользователей электронных сигарет за последние 30 дней и с учетом 30-дневного использования электронных сигарет, было показано, что те, кто тратили больше на Электронные сигареты чаще вызывают боль в груди (9,9\%), кровь при чистке зубов $(17,1 \%)$, язвы или язвы во рту $(8,3 \%)$ и более одной простуды (6,8\%).), чем те, кто не тратится на электронные сигареты. Эти данные подтверждают другое исследование, в котором пользователи электронных сигарет сообщали о чувствительных зубах, язвах во рту, головных болях и симптомах простуды. В проспективном исследовании, подтверждающем концепцию64, по мониторингу изменений в поведении курильщиков, которые перешли на электронные сигареты, наиболее частыми нежелательными явлениями были раздражение горла / рта (35,6\%), сухость в горле / ротовой полости (28,9\%), головная боль $(26,7 \%)$ и сухой кашель $(22,2 \%)$. Эти данные свидетельствуют о том, что электронные сигареты могут оказывать негативное влияние на здоровье полости рта, усиливая раздражение во рту, сухость во рту и образование язв [15].

Способность электронных сигарет к прекращению курения и снижению вреда имеет значительный потенциал для снижения заболеваний полости рта, связанных с табачным дымом, таких как рак полости рта и заболевания пародонта. Общеизвестно, что добиться отказа от курения сложно, и в стоматологических условиях процент отказа от курения в течение года составляет около 15\% при использовании интенсивных вмешательств. Электронные сигареты предоставляют прекрасную возможность улучшить эти показатели, но также могут быть особенно эффективными в качестве «инструмент снижения вреда у 85 процентов пациентов, которые не бросили курить [16].

Необходимо учитывать потенциальное негативное воздействие аэрозоля электронных сигарет на ткани ротовой полости и учитывать преимущества снижения общего воздействия сгоревшего табачного дыма. Большая часть исследований на сегодняшний день посвящена изучению табачного дыма в целом и сбивает с толку термины «никотин» и «курение табака» как взаимозаменяемые. Необходимо завершить специальное исследование воздействия аэрозоля электронных сигарет, и действительно, Национальный институт стоматологических и черепно-лицевых исследований (NIDCR) в США объявил об этом в качестве темы исследования на 2016 год: «Влияние смесей аэрозолей электронных сигарет на Оральный и пародонтальный эпителии» [17].

Актуальные эффекты никотина заслуживают особого внимания. Интересно, что никотин в аэрозоле в первую очередь абсорбируется слизистой оболочкой щек и глотки, а не альвеолами, что демонстрирует возможность 
воздействия на ткани полости рта. Было показано, что никотин обладает ангиогенными и ранозаживляющими свойствами, что потенциально может свидетельствовать о наличии полезные терапевтические показания в полости рта, включая лечение остеонекроза и послеоперационное заживление, особенно при использовании свободных лоскутов. Высказывались опасения относительно его способности стимулировать рост опухоли (при раке легких) с помощью нескольких предложенных механизмов (пролиферация, ангиогенез, миграция и инвазия). На сегодняшний день исследования проводятся в основном in vitro, и клинические исследования не продемонстрировали заметный эффект никотина (например, у пациентов, принимающих никотинзамещающую терапию) [18].
Специалистам по гигиене полости рта может потребоваться документировать наблюдаемые изменения в полости рта своих пациентов, такие как уплотнение слюны, необычные язвы во рту и частоту кариеса. Было бы полезно записывать связанные с употреблением электронных сигарет, тип используемой жидкости, предпочтительные ароматы и концентрацию никотина.

Результаты показывают, что электронные сигареты менее вредны, чем обычные сигареты. Однако потребители электронных сигарет более подвержены изменениям в биологических тканях ротовой полости, чем бывшие курильщики или некурящие. По-прежнему существует явная потребность в развитии новых исследований.

\section{ЛИТЕРАТУРА}

1. Breland A, Soule E, Lopez A, Ramôa C, El-Hellani A, Eissenberg T. Electronic cigarettes: what are they and what do they do? Ann N Y Acad Sci. 2017; 1394(1):5-30.

2. Zhu S-H, Sun JY, Bonnevie E, et al. Four hundred and sixty brands of e-cigarettes and counting: implications for product regulation. Tob Control 2014;23 Suppl 3: iii3-9. doi:10.1136/tobaccocontrol-2014-051670

3. Canadian Tobacco, Alcohol and Drugs Survey (CTADS): summary of results for 2017. Ottawa: Government of Canada; updated 2019-01-04. [Accessed February 4 2019]. Available from: https://www.canada.ca/en/health-canada/services/canadian-tobacco-alcohol-drugs-survey/2017-summary.html

4. Adkison SE, O'Connor RJ, Bansal-Travers M, et al. Electronic nicotine delivery systems: international tobacco control four-country survey. Am J Prev Med 2013;44:20715. doi:10.1016/j.amepre.2012.10.018

5. Hughes K, Bellis MA, Hardcastle KA, et al. Associations between e-cigarette access and smoking and drinking behaviours in teenagers. BMC Public Health 2015;15:244. doi:10.1186/s12889-015-1618-4

6. Bauld L, Angus K, de Andrade M. E-cigarette uptake and marketing. A report commissioned by Public Health England. 2014.

7. Taylor M, Jaunky T, Hewitt $K$, Breheny D, Lowe F, Fearon IM, et al. A comparative assessment of e-cigarette aerosols and cigarette smoke on in vitro endothelial cell migration. Toxicol Lett. 2017;277:123-8.

8. Bergen PL. E-cigarettes are NOT banned in Canada. Tobacco Harm Reduction: News \& Opinions. https://smokles.wordpress.com/2013/02/09/e-cigarettes-are-notbanned-in-canada/ (accessed 22 Apr2015).

9. Effects of tobacco smoke and electronic cigarette vapor exposure on the oral and gut microbiota in humans: a pilot study. CJ Stewart, TA Auchtung, NJ Ajami, K Velasquez, DP Smith, ... PeerJ 6, e4693, 2018. 32. 2018.

10. McRobbie H, Bullen C, Hajek P. Electronic cigarettes for smoking cessation and reduction. The Cochrane Collaboration of Systemtic Reviews 2014; Issue 12.: Art. No.: CD010216.

11. Holliday R, Corson M, Horridge C. Electronic Cigarettes: 'the greatest health advance since vaccinations.' The periodontal perspective. (Conference Poster). British Society of Periodontology Scientific meeting, Newcastle Upon Tyne: 2014.

12. Rouabhia M, Park HJ, Semlali A, Zakrzewski A, Chmielewski W, Chakir J. E-cigarette vapor induces an apoptotic response in human gingival epithelial cells through the caspase-3 pathway. J Cell Physiol. 2017;232(6):1539-47.

13. Hua M, Alfi M, Talbot P. Health-related effects reported by electronic cigarette users in online forums. J Med Internet Res 2013;15: e59. doi:10.2196/jmir.2324

14. Willershausen I, Wolf T, Weyer V, et al. Influence of E-smoking liquids on human periodontal ligament fibroblasts. Head \& Face Medicine 2014;10:39.

15. Manzoli L, La Vecchia C, Flacco ME, et al. Multicentric cohort study on the long-term efficacy and safety of electronic cigarettes: study design and methodology. BMC Public Health 2013;13:883.

16. McRobbie H. E-cigarette briefing. National Center for Smoking Cessation and Training (NCSCT). 2014. Pintado-Palomino K, de Almeida CVVB, Oliveira-Santos C, Piresde-Souza FP, Tirapelli C. The effect of electronic cigarettes on dental enamel color. J Esthet Restor Dent. 2019;31(2):160-5.

17. Zhao J, Nelson J, Dada 0, Pyrgiotakis G, Kavouras IG, Demokritou P. Assessing electronic cigarette emissions: linking physico-chemical properties to product brand, e-liquid flavoring additives, operational voltage and user puffing patterns. Inhal Toxicol. 2018;30(2):78-88.

18. Jeong W, Choi DW, Kim YK, Lee HJ, Lee SA, Park EC, Jang SI. Associations of electronic and conventional cigarette use with periodontal disease in South Korean adults. J Periodontol. 2020;91(1):55-64. 